\title{
LED Therapy
}

National Cancer Institute

\section{Source}

National Cancer Institute. LED Therapy. NCI Thesaurus. Code C67341.

The use of LED light or radiation for treatment of various conditions including skin treatments and chemotherapy. 